\title{
LA INCONSTITUCIONALIDAD DE LA LEY N 21.076 SOBRE MEDIDORES ELÉCTRICOS. EFECTOS JURIIDICO- ECONÓMICOS EN EL MERCADO DE DISTRIBUCIÓN ELÉCTRICA
}

\author{
THE UNCONSTITUTIONALITY OF ACT N ${ }^{\circ}$ 21,076 ON \\ ELECTRICAL METERS. LEGAL-ECONOMIC EFFECTS IN THE \\ POWER DISTRIBUTION MARKET
}

RAFAEL PLAZA REVECO*

\section{RESUMEN}

La Ley $\mathrm{N}^{\circ} 21.076$ introdujo el art. 139 bis a la Ley General de Servicios Eléctricos, el cual amplió la red de distribución eléctrica hasta incluir el medidor de consumo, y radicó en las distribuidoras la titularidad del dominio sobre dicho equipo. Este artículo de investigación sostiene la inconstitucionalidad de fondo de la Ley $\mathrm{N}^{\circ} 21.076$; y la existencia de un trade-off económico favorable a los intereses de empresas distribuidoras en desmedro de los usuarios regulados. Cuestiona también -en hipótesis determinadas- incluir en tarifas el financiamiento de instalaciones de reemplazo y servicios asociados. La metodología de la investigación comprende el análisis de la Ley $\mathrm{N}^{\circ} 21.076$ frente al de las normas constitucionales, administrativas y regulatorias del sector y mercado relevante, conjuntamente con el análisis económico de su interacción. El estudio concluye que el art. 139 bis es inconstitucional y -como tal-pasible

\footnotetext{
* Abogado, Licenciado en Ciencias Jurídicas y Sociales, Universidad de Chile (UCh). Diplomado en Tributación Nacional, Facultad de Economía y Negocios de la Universidad de Chile (UCh). LL.M. in International Taxation, New York University (NYU). LL.M./ PhD Energy, Natural Resources \& Environmental Law, University of Melbourne (UNIMELB). Post PhD China University of Geosciences (CUG). Académico y Sub Director del Departamento de Derecho Económico de la Facultad de Derecho de la Universidad de Chile (UCh). Correo electrónico: rplaza@derecho.uchile.cl. ORCID: https://orcid. org/0000-0003-3515-0132. PUBLONS ID: H-1499-2017.
}

Artículo recibido para su evaluación el 27 de agosto de 2019, y aceptado para su publicación el 15 de junio de 2020 . 
de variadas acciones constitucionales, administrativas y jurisdiccionales. Concluye también y en todo caso, la derogación tácita de una función pública de arbitraje, la lesión a la autonomía de un grupo intermedio y la desaparición de contrapesos de los usuarios regulados al poder de mercado de las concesionarias de distribución en cuanto monopolistas naturales.

Palabras clave: Ley 21.076, Ley eléctrica, servicio público de distribución eléctrica, medidor eléctrico, expropiación, poder de mercado.

\section{ABSTRACT}

Act Nr. 21.076 introduced section 139 bis to the Electric Services General Act, that expanded the power distribution network to include consumption meters and placed equipment ownership on distributors. This paper advances the substantial unconstitutionality of Act Nr. 21.076 as well as the existence of an economic trade-off favorable to the interests of distribution companies, to the detriment of regulated users. It also questions -in certain hypotheses- to include in tariffs the financing of replacement equipments and associated services. The methodology of the enquiry is based on the analysis of Act Nr. 21.076 against the constitutional, administrative and regulatory framework of the industry sector and relevant market, together with the economic analysis of their interaction. The study concludes that section 139 bis suffers from unconstitutionality and, therefore, is subject to an array of constitutional, administrative and jurisdictional actions. It also concludes, at any rate, on a tacit derogation of a public adjudicatory function, the damage to the autonomy of an intermediate group, and the loss of counterweights to the market power of distribution concessionaires as natural monopolists, to the detriment of regulated users.

Keywords: Act Nr. 21.076, electric services general act, public service on power distribution, power meter, expropriation, market power.

\section{LA DISTRIBUCIÓN Y LOS EQUIPOS ELÉCTRICOS ASOCIADOS}

Debe precisarse que el segmento de la industria del que se ocupará esta pesquisa es el de la distribución eléctrica $\mathrm{y}$, específicamente, como 
mercado relevante dentro de aquel segmento, el del suministro eléctrico en redes de media y baja tensión.

1. El servicio público eléctrico de distribución. Tipos y contexto económicojurídico

De acuerdo con la Ley General de Servicios Eléctricos (en adelante, indistintamente, Ley Eléctrica o LGSE), dicho suministro es de dos tipos: un servicio público eléctrico de distribución (en adelante, SPED) y otros suministros en las mismas tensiones. Lo distintivo de la tipología, entonces, es que en un caso se está en presencia de un servicio público y en el otro no, cuestión clave que tiene implicancias jurídico-económicas muy importantes.

En efecto, el sistema o red de distribución eléctrica en media y baja tensión es un servicio público, como lo dispone el artículo 7 de la LGSE; y, por lo mismo, es muy importante delimitar su esfera de acción y las obligaciones que la ley impone a los distribuidores.

Así, que el suministrar electricidad en media y baja tensión constituya un servicio público implica jurídicamente: a) una actividad inmaterial, b) considerada de interés público, c) que se rinde o se presta ya por el Estado directamente o por un tercero en su nombre, en virtud de una concesión pública, d) que recae sobre un bien determinado, y e) cuya disponibilidad está asegurada y de la que ultima facie es responsable el Estado.

Pero también implica, ahora desde el punto de vista económico, que dicha actividad provea a una necesidad económica vinculada a un bien público, esto es, no rival ni exclusivo; ${ }^{1}$ y en que el precio o contraprestación a percibir por el prestatario del servicio (sea el Estado o el concesionario) no se alcanza en condiciones de competencia perfecta sino que, expresamente, mediante una intervención regulatoria destinada a moderar el poder de mercado o derechamente las utilidades de los agentes económicos llamados a prestar dicho servicio. ${ }^{2}$

La ley regula a las empresas concesionarias de SPED y les impone obligaciones variadas como, por ejemplo, las que prescribe el artículo 8 ter de la LGSE: constituirse como sociedades anónimas sujetas a las normas

\footnotetext{
${ }^{1}$ Para la economía clásica, bienes no exclusivos son aquellos cuyo consumo no excluye el de los demás; en tanto que no rivales son aquellos cuyo uso por un agente no merma el que puedan hacer otros distintos. El costo marginal de un nuevo usuario es cero. SAmuelson, Paul, "The Pure Theory of Public Expenditure”, The Review of Economics and Statistics, 1954, vol. 36, No 4, pp. 387-389.

${ }^{2}$ Para cada caso, la tarifa de suministro regulada y contratada.
} 
sobre operaciones entre partes relacionadas de la Ley $\mathrm{N}^{\circ}$ 18.046; tener giro exclusivo de distribución de energía eléctrica; o, si se trata de concesionarias constituidas como cooperativas según el Decreto con Fuerza de Ley $\mathrm{N}^{\circ} 5$, de 2003, de Economía, y autorizadas a desarrollar otras actividades o giros distintos al de distribución, están obligadas a llevar una contabilidad separada y fidedigna que permita establecer los resultados de gestión económica en el giro de distribución de forma diferenciada.

La regulación jurídico-económica de la distribución es lógica si se observa la alta concentración económica de la distribución eléctrica, basada en la propiedad y/o administración de las redes y que le otorgan una clara caracterización si no monopólica de tipo natural, al menos oligopólica a nivel de segmento (distribución). En efecto, en Chile, más de 6.5 millones de clientes son servidos por sólo una treintena de compañías, ${ }^{3}$ de las cuales ENEL Distribuzione SpA, CGE Distribución S.A., CHILQUINTA S.A. y $S A E S A$ concentran la mayor parte del mercado relevante de distribución eléctrica concesionada.

La teoría económica supone a los monopolios naturales -como al de la distribución de energía eléctrica- una alta eficiencia productiva, porque es más eficiente un distribuidor que muchos; $\mathrm{y}$, con esa premisa, es válido que les suponga igualmente utilidades extraordinarias, porque el monopolio se trata de ellas. Por lo mismo, la regulación o la labor del Estado aparece como una fórmula de compromiso para no renunciar a la eficiencia máxima que reporta un único agente, por un lado; y para evitar los potenciales abusos y excesos del mismo monopolista, o de un grupo reducido con alto poder de mercado, no regulado, por otro. El hecho que la electricidad misma sea un bien económico que carece de sustitutos y que exista ingente asimetría de información entre el consumidor y el concesionario que se la suministra, no sólo justifican la intervención regulatoria y supervigilante del Estado, sino que validan la existencia misma del servicio público (el SPED) por involucrar un bien o interés público.

Finalmente y para completar la tipología inicial, los suministros que no constituyen SPED se diferencian en que no son concesibles y se rigen ya por contratos especiales, ya por permisos eléctricos. ${ }^{4}$

\footnotetext{
${ }^{3}$ De acuerdo al decreto tarifario vigente, DS 11T, 2016, Ministerio de Energía, modificado por el DS 5T, 2018, Ministerio de Energía -cursado este último con alcance por la Contraloría General de la República- las entidades afectas son 32.

${ }^{4}$ Son los suministros contemplados en los arts. 8 y 16 de la LGSE.
} 
2. Marco regulatorio previo a la Ley $N^{\circ} 21.076$ en relación con equipos eléctricos (empalmes y medidores) y servicios asociados al suministro

Desde los albores de la electricidad en Chile y hasta la dictación de la primera Ley Eléctrica en 1925, la venta de energía y potencia eléctrica se contabilizaba usando medidores de corriente, que expresaban el flujo de carga de electrones en el conductor en Ampère/hr (Amp/hr).

La primera LGSE contempló cambiar el modo de contabilizar el suministro desde un sistema que cobraba la energización simple por otro que apuntaba al cobro por consumo real. Así dispuso entonces que, en un lapso de diez años (hasta 1935), los medidores debían ser reemplazados por otros que registraran la energía efectivamente consumida y, como tal, expresada en kilowatt/hr $(\mathrm{kWh})$.

El mandato legal fue implementado a través de una norma técnica de seguridad, la NSEG 3 E.n71, de la cual cabe destacar tres características: a) Estableció un régimen mixto de propiedad sobre los medidores y empalmes, los que o bien podían ser enteramente privados, del usuario o cliente que los adquiría para sí, o bien de la distribuidora (ya fuere ésta pública o privada), quien los arrendaba a su cliente, con el respectivo cobro en la cuenta de luz; ${ }^{5}$ b) Determinó que la verificación de los medidores y empalmes era de competencia de la Dirección de Servicios Eléctricos, antecesora de la actual Superintendencia de Electricidad y Combustibles (en adelante, SEC); y c) Dispuso que la calibración de los medidores quedaba regida, eventualmente, por un contrato celebrado con uno u otro propietario (cliente/distribuidora).

En relación con el régimen de propiedad de los medidores y empalmes, actualmente, es el Decreto Supremo No 197 de 2009, de Economía (en adelante, DS 197), ${ }^{6}$ el que fija los precios de los servicios no consistentes en suministros de energía, pero asociados a la distribución eléctrica, como el retiro e instalación de dichos equipos.

A la fecha, la norma técnica que fija las características de los llamados Sistemas de Medición, Monitoreo y Control (en adelante, SMMC) vulgarmente llamados "medidores inteligentes"- es la Resolución Exenta No 468, de 12 de agosto de 2019, de la Comisión Nacional de Energía. La

\footnotetext{
${ }^{5}$ Vía partida “servicios asociados", regulados por el DS 197, 2009, del Ministerio de Economía.

${ }^{6}$ Decreto Supremo No 197, de 2009, del Ministerio de Economía, que fija precios de servicios no consistentes en suministros de energía, asociados a la distribución eléctrica (en adelante, DS 197, 2009).
} 
Resolución fijó el Anexo Técnico de los SMMC a que se refiere la Norma Técnica de Calidad de Servicio para Sistemas de Distribución fijada, a su vez, por la Resolución Exenta № 706, de 7 de diciembre 2017, de la misma Comisión.

Por lo antes referido, ni el reemplazo de medidores y empalmes, ${ }^{7}$ ni el de otros cambios en la modalidad de suministro son algo inédito en la historia de la normativa eléctrica chilena, aunque ella siempre había respetado el derecho de propiedad constituido sobre las instalaciones eléctricas y equipos de medición.

\section{La Ley $N^{\circ}$ 21.076. Sorprendente y singular historia de una 'ley mutante'}

Con ocasión de los desastres naturales que con cierta regularidad asolan a nuestro país, ya en 2010 surgió una propuesta de ley que apuntó a hacer responsables a las empresas distribuidoras del recambio de medidores en situaciones no atribuibles al usuario, ${ }^{8}$ iniciativa que entonces no prosperó.

La idea reflotó en 2015 -motivada por el terremoto de Coquimbo- con una moción legislativa originada en la Cámara de Diputados y que sólo apuntaba a obligar a las distribuidoras a solventar el retiro y reposición de empalmes y medidores en caso de inutilización por fuerza mayor. ${ }^{9}$

Aunque prima facie la inspiración podía parecer noble y su objeto muy concreto, lo cierto es que en ambas ocasiones resulta muy debatible

\footnotetext{
${ }^{7}$ El DS 197, 2009, del Ministerio de Economía, define el empalme, para efectos de su ejecución e instalación, como el "conjunto de elementos que conectan una instalación interior a la red de distribución" y "constituido por la acometida y la bajada hasta la caja de medición, incluyendo la instalación de ésta y la del interruptor termo magnético o del equipo de protección que corresponda" (art. 1, I.2., letra L); y aunque para efectos de instalación o retiro, el art. $1^{\circ}$, I.2., letra F del DS 197 no contempla una definición expresa de medidor, sí contiene parámetros útiles para caracterizarle: 1) existen tres subtipos de medidores (monofásico, trifásico propiamente tal y trifásico con indicador de demanda máxima); 2. Tanto su caja como las protecciones o transformadores de corriente o tensión, u otro tipo cualquiera de equipamiento asociado a la medida pero ajeno al propio medidor no se incluyen en el servicio de instalación o retiro (de medidor) que regula el decreto.

${ }^{8}$ CÁmara de Diputadas y Diputados, "Sobre reposición de empalmes y medidores eléctricos", Proyecto de Ley Boletín N 6899-03, Legislatura 358, Sesión 9, 14 de abril de 2010. Moción de los H. senadores Sra. Ximena Rincón y Sr. Eugenio Tuma.

${ }^{9}$ CÁmara de Diputadas y Diputados, "Modifica la Ley General de Servicios Eléctricos para imponer a la empresa distribuidora de energía la obligación de solventar el retiro y reposición del empalme y medidor en caso de inutilización de las instalaciones por fuerza mayor", Proyecto de Ley Boletín №10331-08, Legislatura 363, Sesión 78, 8 de octubre de 2015. Moción parlamentaria de los H. diputados señores Gahona, Alvarado, Hasbún, J.A. Kast, Morales, D. Núñez, Trisotti y Ward y de las diputadas señoras Molina y Nogueira.
} 
el carácter populista de la medida; y aún más en la segunda, en donde se afirma que la idea matriz del proyecto de ley original es enmendar la injusticia que supone el que las distribuidoras exijan sea de cargo de los usuarios (damnificados en el terremoto) el retiro y reposición de servicios de empalme y de medidor eléctricos prestados por ellas y en que el contenido del proyecto de la Cámara haya mutado de objeto principal y alcance de una manera tan sorprendente en el Senado.

Interesa aquí ilustrar el punto del cambio radical de fondo en el proyecto de ley (Boletín $\mathrm{N}^{\mathrm{0}}$ 10.331-08). La tabla a continuación compara el texto original del proyecto de ley y los textos finales aprobados por la Cámara y el Senado del artículo único que el proyecto introducía a la Ley Eléctrica.

\begin{tabular}{|c|c|c|}
\hline $\begin{array}{c}\text { Cámara de Diputados de la } \\
\text { República. Proyecto de ley } \\
\text { original. }{ }^{10}\end{array}$ & $\begin{array}{c}\text { Cámara de Diputados de la } \\
\text { República. Primer trámite } \\
\text { constitucional. }{ }^{11}\end{array}$ & $\begin{array}{l}\text { Senado de la República. } \\
\text { Segundo trámite } \\
\text { constitucional. }{ }^{12}\end{array}$ \\
\hline $\begin{array}{l}\text { "Artículo } 139^{\circ} \text { bis.- El retiro } \\
\text { y reposición del empalme y } \\
\text { medidor será íntegramente } \\
\text { de cargo de la empresa } \\
\text { distribuidora de energía, } \\
\text { siempre que la inutilización } \\
\text { de la obra se haya producido } \\
\text { por una fuerza mayor como un } \\
\text { sismo, salida de mar, temporal } \\
\text { u otra calamidad y en el caso } \\
\text { en que la autoridad competente } \\
\text { haya decretado zona de } \\
\text { catástrofe" }\end{array}$ & $\begin{array}{l}\text { "Artículo } 139^{\circ} \text { bis.- El retiro } \\
\text { y reposición del empalme y } \\
\text { medidor será íntegramente } \\
\text { de cargo de la empresa } \\
\text { distribuidora de energía, } \\
\text { siempre que la inutilización de } \\
\text { la obra se haya producido por } \\
\text { una fuerza mayor, como sismo, } \\
\text { salida de mar, temporal u otra } \\
\text { calamidad, y que la autoridad } \\
\text { competente haya decretado } \\
\text { zona de catástrofe. Este retiro } \\
\text { y reposición no quedará } \\
\text { condicionado a la existencia } \\
\text { de morosidad en la cuenta o } \\
\text { saldo pendiente en el momento } \\
\text { en que se produzca la fuerza } \\
\text { mayor y se haya decretado por } \\
\text { la autoridad competente zona } \\
\text { de catástrofe." }\end{array}$ & $\begin{array}{l}\text { "Artículo } 139 \text { bis.- El empalme } \\
\text { y el medidor son parte de la red } \\
\text { de distribución y, por tanto, de } \\
\text { propiedad y responsabilidad de } \\
\text { la concesionaria del servicio } \\
\text { público de distribución o de } \\
\text { aquel que preste el servicio } \\
\text { de distribución. Los decretos } \\
\text { tarifarios a que se refieren } \\
\text { los artículos 120, } 184 \text { y } \\
\text { 190, o el que los reemplace, } \\
\text { determinarán la forma de } \\
\text { incluir en sus fórmulas } \\
\text { tarifarias la remuneración de } \\
\text { estas instalaciones, así como } \\
\text { las condiciones de aplicación } \\
\text { de las tarifas asociadas a ellas." }\end{array}$ \\
\hline
\end{tabular}

${ }^{10}$ Cámara de Diputadas y Diputados, cit. (n. 9).

${ }^{11}$ Cámara de Diputadas y Diputados, Oficio №12.756, del 16 de agosto de 2016, en que envía el Proyecto de Ley Boletín No 10.331-08, aprobado, a la Cámara Revisora.

${ }^{12}$ Senado, Oficio No 40/SEC/18, del 17 de enero de 2018, en que devuelve el Proyecto de Ley Boletín No 10.331-08, aprobado con modificaciones, a la Cámara de Diputadas y Diputados. 
La idea central del proyecto original fue imponer a la empresa distribuidora de energía la obligación de solventar el retiro y reposición del empalme y medidor en caso de inutilización de las instalaciones por fuerza mayor. ${ }^{13}$ Como se puede observar en la tabla comparativa, en el texto permanente finalmente aprobado por el Senado, poco o nada quedó de la sencilla idea matriz de la Cámara de origen. En el Senado, en efecto, las enmiendas introducidas fueron votadas -en virtud de acuerdo de comités parlamentarios, de manera económica, sin discusión; y, finalmente, aprobadas por la Cámara de origen el 25 de enero de 2018 con 91 votos a favor, sin votos en contra y sin abstenciones. ${ }^{14}$

La historia fidedigna del establecimiento de la ley puede consultarse públicamente, y en ella se encuentra la intervención de la Subsecretaria de Energía de la época, Sra. Jimena Jara, ante la Comisión de Minería y Energía del Senado abogando "por la conveniencia de que su articulado precise a quién corresponde la titularidad del derecho de dominio sobre el medidor". ${ }^{15}$

Sorprendente, asimismo, fue la balística velocidad de tramitación del proyecto en la Cámara revisora -sólo doce días efectivos- que tuvo durante el mes de enero de 2018, ${ }^{16}$ breve lapso en que operó la notable mutación de fondo que se describirá. En efecto, como explicaremos en la sección II, la altruista idea original de reparar una injusticia mutó al punto de generar otra mayor: ampliando el dominio de las distribuidoras (la red) a costa de despojar del suyo a los usuarios, sin indemnizarles.

Finalmente, y ya desde el sólo punto de vista formal, la Ley $\mathrm{N}^{\mathrm{o}} 21.076$ es singular. Dos botones de muestra: a) Existe una notable incongruencia

\footnotetext{
${ }^{13}$ Comisión de Minería y Energía de la Cámara de Diputadas y Diputados, "Informe de Comisión de Minería y Energía en Sesión 21, Legislatura 364, Cámara de Diputadas y Diputados, 11 de marzo de 2016", en: Biblioteca del Congreso Nacional de Chile (Eds.), Historia de la Ley N ${ }^{o}$ 21.076, que modifica la Ley General de Servicios Eléctricos para imponer a la empresa distribuidora de energía la obligación de solventar el retiro y reposición del empalme y medidor en caso de inutilización de las instalaciones por fuerza mayor, 2019, p. 5, disponible en: https://www.bcn.cl/historiadelaley/nc/ historia-de-la-ley/7500/.

${ }^{14}$ Biblioteca del Congreso Nacional de Chile, cit. (n. 14), p. 61-62.

${ }^{15}$ Comisión de Minería y Energía del Senado, "Informe de Comisión de Minería y Energía en Sesión 78, Legislatura 365, Senado, 5 de enero de 2018", en: Biblioteca del Congreso Nacional de Chile, cit. (n. 14), p. 44.

${ }^{16}$ Desde el 5 de enero de 2018, fecha de la cuenta en la Comisión de Minería y Energía del Senado del Oficio CNE $\mathrm{N}^{\mathrm{o}} 715$, de 19.12.17, que respondió a la solicitud de antecedentes asociados a proyectos piloto de instalación de medidores inteligentes y propiedades de medidores y empalmes y del primer informe de la Comisión, hasta el 17 de enero del mismo año, fecha de votación y del oficio de devolución a la Cámara de origen con modificaciones.
} 
entre el título y las disposiciones de fondo principales de la norma, que vela el objeto real de la ley (despojo y traspaso de titularidad de dominio inconstitucionales, afectación de potestades públicas y trade-off económico desfavorable a los usuarios regulados) y torna su título equívoco o al menos incompleto, y sin embargo, notoriamente atractivo para las masas al apelar a una obligación de pago por los concesionarios; y b) En simple disposición transitoria, la atractiva obligación de pago - que de acuerdo al título de la ley pareciera ser general- es en realidad producto de una hipótesis residual (caso fortuito), de ocurrencia eventual y, además, extremadamente restringida en su alcance efectivo por la imposición de requisitos reglamentarios (estado de catástrofe decretado). En tanto, son los efectos velados ya descritos los que componen las normas permanentes de la ley y de los que nada cabe advertir en el título.

4. Qué dispone la normativa actual: el art. 139 bis de la LGSE, sobre el régimen de propiedad de los equipos

El art. 139 bis de la LGSE introducido por la Ley No 21.076 dispone, de manera permanente, que dos instalaciones eléctricas, el empalme y el medidor, pasan a formar parte de la red de distribución eléctrica; y, por tanto, a ser de propiedad y responsabilidad del concesionario o prestador del servicio público eléctrico de distribución, ${ }^{17}$ un cambio inédito en la legislación eléctrica nacional.

Adicionalmente, en el inciso $1^{\circ}$ de su art. $1^{\circ}$ transitorio, la Ley $\mathrm{N}^{\circ}$ 21.076 dispuso que -a contar de su publicación en el Diario Oficial el 27 de febrero de 2018- la titularidad del dominio de los medidores o empalmes se mantendría inalterada, hasta que su cambio por parte de la concesionaria o prestataria del servicio público de distribución eléctrica, fuere necesaria, en razón de algunos de estos dos supuestos: requerirlo así la red eléctrica "para el debido cumplimiento de la normativa vigente"; o, cuando fuere necesaria la reposición de dichos equipos -por inutilización o destrucción- causada por fuerza mayor en estado de excepción constitucional de catástrofe decretada por la autoridad, caso contemplado en su inciso $2^{\circ} .{ }^{18}$

${ }^{17}$ En lo sucesivo, y en relación con el art. 139 bis LGSE, la alusión al concesionario del servicio público de distribución incluye también a aquel que preste el servicio de distribución.

${ }^{18}$ La obligación de asumir el costo íntegro del recambio de las instalaciones en este preciso supuesto (fuerza mayor del inc. $2^{\circ}$ art. $1^{\circ}$ transitorio) no queda condicionado a la existencia de servicios impagos por parte del usuario propietario del medidor o empalme, al tiempo de la fuerza mayor y se decrete el 


\section{Relevancia de los equipos de medición}

En 2012, durante el primer mandato del Presidente Sebastián Piñera, se promulgó la Ley No 20.571. Esta ley incorporó a la LGSE -por primera vezinstituciones vinculadas a la generación distribuida y la gestión de demanda, como los Pequeños Medios de Generación Distribuidos (PMGD), el Smart Metering y el Net Billing. ${ }^{19}$ En síntesis, la ley reconoció el derecho de los propietarios de medios de generación distribuida a inyectar sus excedentes de energía a la red, recibiendo una compensación económica por ello. ${ }^{20} \mathrm{El}$ objetivo de política pública es la configuración de una "red inteligente" y para ello se requieren SMMC, equipos de nueva tecnología digital que reemplacen a la infraestructura analógica actual.

Sin embargo, no todos los empalmes y medidores eléctricos existentes en Chile se verán afectados por la Ley $N^{\circ} 21.076$. Por ejemplo, los suministros de los arts. 8 y 16 de la LGSE quedan fuera del ámbito de aplicación de la Ley $\mathrm{N}^{\circ} 21.076$ porque no constituyen servicio público eléctrico de distribución y se rigen por permisos eléctricos y contratos particulares, respectivamente, y en que la propiedad, operación y mantenimiento de los equipos asociados se acuerda previamente entre los interesados.

El ámbito de aplicación de la Ley $N^{\circ} 21.076$ abarca, entonces, sólo los suministros que constituyen SPED y que, por lo mismo, son suministros concesionados.

Lo anterior es de extrema relevancia porque un servicio de esas características involucra precisamente el interés público a lo largo de todo su proceso de desarrollo. Como sabemos, al importar interés público el SPED requiere concesión. ${ }^{21}$ La importancia de esta exigencia se manifiesta claramente en dos características del suministro de SPED: primeramente, que la concesión deba adjudicarse mediante licitación pública cuando haya

estado de catástrofe.

${ }^{19}$ A nivel de PMGD, la generación distribuida alcanza más de $500 \mathrm{MW}$; y más de 20 MW de capacidad instalada a nivel de net billing. Véase NoтісіA: "2019, un año para las grandes definiciones de una nueva distribución eléctrica”, página de Alster Legal, 23 de enero de 2019, comentario disponible en línea: https:// www.alsterlegal.com/2019/01/23/2019-ano-las-grandes-definiciones-una-nueva-distribucionelectrica/, consultada al 23 de mayo de 2019.

${ }^{20}$ Los excedentes inyectados son valorizados al precio de la energía que las compañías distribuidoras cobran a sus clientes regulados, por lo que se traducen en descuentos en los cargos por energía de la cuenta del usuario. También es posible pagos monetarios cuando existan excedentes valorizados acumulados sin descontar al fin del período convenido en el respectivo contrato de conexión.

${ }^{21}$ Art. $2 \mathrm{~N}^{\mathrm{o}} 2$ LGSE. 
al menos dos interesados en la misma área; y en segundo lugar que, una vez adjudicada, la concesión eléctrica de distribución es -por regla generalintransferible. $^{22}$

\section{LA GARANTÍA CONSTITUCIONAL DEL DOMINIO Y LOS EMPALMES $Y$ MEDIDORES}

El art. 19 en sus $\mathrm{N}^{\circ}$ s. 23 y 24 de la Constitución Política (CPR) garantizan la libertad para adquirir toda clase de bienes y el derecho de propiedad ya constituido, en sus diversas especies, sobre toda clase de bienes corporales e incorporales. De acuerdo con la Constitución, sólo la ley puede establecer no sólo el modo de adquirir la propiedad; sino que también nadie puede ser privado de ella o del bien sobre que recae, sino en virtud de ley general o especial que autorice la expropiación por causa de utilidad pública o de interés nacional calificada por el legislador. En cualquier caso, prescribe la Constitución, el expropiado tendrá siempre derecho a indemnización por el daño patrimonial efectivamente causado y la toma de posesión material del bien expropiado no puede tener lugar sino hasta el pago completo de la indemnización expropiatoria.

Los empalmes y medidores eléctricos son bienes corporales. El dominio que recae sobre cualquiera de estas dos instalaciones eléctricas está, entonces, amparado constitucionalmente con independencia de sobre quién recae su titularidad.

Hasta antes de la introducción del art. 139 bis la propiedad de esos equipos podía recaer tanto sobre las compañías distribuidoras como sobre sus clientes o usuarios. El art. $1^{\circ}$ transitorio de la Ley $\mathrm{N}^{\circ} 21.076$ es prueba palmaria de ello.

Lo medular aquí, entonces, es que no sólo los medidores y los empalmes eléctricos son y han sido objeto de dominio reconocido por el ordenamiento legal, reglamentario y técnico de la industria eléctrica en general y del segmento de distribución en específico, sino que también su heterogénea titularidad; y que su permanencia en el patrimonio de su respectivo titular está amparada por la Constitución.

\footnotetext{
${ }^{22}$ La exigencia de licitación pública y la intransferibilidad de la concesión de SPED están contempladas en el art. 26 LGSE. El procedimiento mismo de licitación pública está en el art. 131 y ss. LGSE. Sobre la intransferibilidad general de la concesión véase art. 47 de la LGSE.
} 
Esta investigación sostiene la inconstitucionalidad de fondo de la Ley $\mathrm{N}^{\circ} 21.076$, ergo del art. 139 bis de la LGSE, por cuatro motivos principales: primero, por contravenir la garantía del art. $19 \mathrm{~N}^{\circ} 24$ de la CPR despojando sin indemnización; segundo, limitar la garantía del art. $19 \mathrm{~N}^{\circ} 23$ de la CPR para adquirir el dominio de equipos eléctricos para conectar a la red de distribución; tercero, contravenir -de iure- la función administrativa propia de un servicio público atingente a una actividad económica de carácter monopólica (distribución eléctrica a clientes regulados); y, finalmente, por imponer el financiamiento del recambio de medidores en los usuarios.

\subsection{Contravención al art. $19 N^{\circ} 24$ de la CPR}

El art. 139 bis de la LGSE despertó una polémica de alcance nacional en relación con la contribución a los costos de desmantelamiento y retiro de empalmes y medidores analógicos y su sustitución por los nuevos medidores "inteligentes". ${ }^{23}$ Sin embargo, nadie pareció advertir ni mucho menos aquilatar la enorme relevancia jurídico-patrimonial de introducir como lo hizo -nada más y nada menos- un cambio completo en el régimen de propiedad de las instalaciones eléctricas que nos ocupan (empalmes y medidores), en su titularidad, en total contravención a los requerimientos constitucionales para privar a alguien -en este caso los usuarios dueños de tales equipos- de su dominio y del bien sobre el que recae. A continuación, expondremos la forma en que se produce esta infracción constitucional.

Para comenzar, el artífice del cambio en el régimen de propiedad de los empalmes y medidores eléctricos cuya constitucionalidad ponemos en entredicho es el art. $1^{\circ}$ transitorio de la Ley $\mathrm{N}^{\circ} 21.076$, pues es la norma que determina las hipótesis en que opera el cambio de titularidad del dominio de los equipos que interesan.

\footnotetext{
${ }^{23}$ La polémica sobre la materia, en todo caso, no resulta infundada si se toma en cuenta que afecta a más de 6,7 millones de usuarios residenciales. Ministerio de Energía, "Ministra de Energía confirma la voluntariedad para recambio de los medidores inteligentes y anuncia que las distribuidoras eléctricas devolverán los dineros cobrados", en: http://www.energia.gob.cl/tema-de-interes/ministra-de-energiaconfirma-la Consultado el 11 de junio de 2019. A fines de 2017, de un total de 6.147.779 medidores, el $70 \%$ era de propiedad de los clientes y sólo el $30 \%$ restante de propiedad de las distribuidoras. Y de un total de 5.983.279 empalmes, el 84,4\% era de propiedad de los usuarios y sólo el 15,6\% de las empresas concesionarias. Comisión NACIONAL de Energía, Oficio Ord. № 715/2017, del 19 de diciembre de 2017, dirigido a la Comisión de Minería y Energía del Senado.
} 
La primera hipótesis en que los usuarios dueños de medidores o empalmes pierden la titularidad de su dominio es cuando la concesionaria de distribución los haya cambiado - a partir del 28 de septiembre de $2018^{24}$ - de acuerdo a los requerimientos de la red eléctrica para el debido cumplimiento de la normativa vigente. De acuerdo con el DS $197,{ }^{25}$ y por razones técnicas fundadas, el concesionario podría requerir este cambio sin la conformidad del usuario. Pero hay más, en este supuesto del art. $1^{\circ}$ transitorio el servicio de retiro o desmantelamiento y el de ejecución o instalación del nuevo medidor (inteligente) o empalme resultan, de acuerdo con la norma técnica vigente (DS 197), de cargo del usuario.

La segunda hipótesis en que los usuarios perderán la titularidad del dominio sobre sus medidores o empalmes es cuando el concesionario -con posterioridad al 27 de febrero de 2018- los cambie en la hipótesis del inc. $2^{\circ}$ del art. $1^{\circ}$ transitorio, esto es, haber resultado inutilizados o destruidos por fuerza mayor y en que se haya decretado estado de catástrofe. Sólo en esta hipótesis el costo de los servicios de retiro o desmantelamiento y ejecución o instalación de los nuevos equipos lo asumirá íntegramente la concesionaria. ${ }^{26}$

De los artículos transitorios y permanente de la Ley $\mathrm{N}^{\circ} 21.076$ interesa -muy especialmente- destacar los siguientes aspectos: a) el cambio por parte de la concesionaria es el hecho jurídico que afecta la titularidad del dominio de los equipos, ${ }^{27}$ b) la afectación de la titularidad dominical involucra no sólo a la de los equipos antiguos, ${ }^{28}$ sino que también a la de los equipos

\footnotetext{
${ }^{24}$ Fecha de publicación en el D.O. del DS 5T, 2018, del Ministerio de Energía, que fija las fórmulas tarifarias para los suministros sujetos a precios regulados del DS 11T, 2016, del Ministerio de Energía. ${ }^{25}$ DS 197, 2009, del Ministerio. de Economía.

${ }^{26}$ Incidentalmente éste es el único, de varios supuestos posibles, que justifica el atractivo título conferido a la Ley $\mathrm{N}^{\circ} 21.076$.

${ }^{27} \mathrm{Si}$ no fuera por el cambio radical en la configuración de la red de distribución y en el régimen de propiedad de medidores y empalmes que introduce la norma permanente de la Ley $\mathrm{N}^{\circ} 21.076$-el art. 139 bis LGSE-, para mantener la titularidad de su dominio sobre tales equipos, el cliente podría simplemente haber usado el expediente de cambiarlos por sí mismo o por un tercero (si estuvieren debidamente calificados por la SEC, por ejemplo), pues la norma transitoria discurre sobre la base de un cambio efectuado "por parte de la concesionaria". Además de preservar la titularidad del dominio, la posibilidad de admitir cambios de los equipos por parte de terceros distintos al concesionario hubiera constituido no sólo una oportunidad de negocio privado; sino un importante contrapeso al poder de mercado monopólico de las distribuidoras.

${ }^{28}$ Ha de entenderse, técnicamente, que el dominio sobre los equipos antiguos se resuelve; pues en parte alguna la ley prescribe que su titularidad pase al concesionario, sino sólo que el usuario la mantiene hasta el cambio, ergo, que la pierde después.
} 
reemplazantes aunque hubieren sido cambiados a expensas del usuario, ${ }^{29}$ c) resulta notable que el art. $1^{\circ}$ transitorio aluda sólo al costo de servicios asociados al cambio de equipos, ${ }^{30}$ pero nada diga del financiamiento -del costo- de los equipos mismos; $y$, finalmente, d) no huelga consignar que, en todos los demás cambios de equipos no realizados por el concesionario por imperativo normativo o motivados por circunstancias atribuibles al usuario, esto es, no constitutivas de fuerza mayor o incluso en ellas cuando no se decretare estado de catástrofe, el costo de los servicios asociados al cambio recae en el usuario. ${ }^{31}$

Sólo por excepción la Constitución Política permite desposeer a alguien de su dominio, basándose en la función social de la propiedad. Este criterio -sin embargo- no es definido por ella, pero sí caracterizado indirectamente a través de ciertos parámetros: "los intereses generales de la Nación, la seguridad nacional, la utilidad y la salubridad públicas y la conservación del patrimonio ambiental". 32

El Decreto Ley $\mathrm{N}^{\circ} 2.186$, de $1978,{ }^{33}$ es la norma que -mediante una declaración general de interés nacional o utilidad pública- autoriza a un determinado órgano administrativo para iniciar el procedimiento expropiatorio en casos generales múltiples. Configura, lo que en doctrina se llama una "ley de expropiabilidad"; por oposición a una "ley expropiante", aquella -menos común- que expresamente dispone la expropiación, con fundamentos precisos y determinados de naturaleza constitucional o legal. ${ }^{34}$

Pues bien, ninguna de esas categorías resulta aplicable a la Ley $\mathrm{N}^{\circ}$ 21.076 que, rehuyendo expresar derechamente que los expropia ${ }^{35}$ no sólo dispone el cambio en la titularidad del dominio de empalmes y medidores eléctricos; sino que, aún peor, lo hace sin justificar de manera alguna la

\footnotetext{
${ }^{29}$ Ver citas n. 8 y 23.

${ }^{30}$ Servicios asociados a la distribución que no constituyen suministro, del DS 197, 2009, de Economía (retiro o desmantelamiento y ejecución o instalación de empalmes y medidores).

${ }^{31}$ La única excepción podría ser que éste tenga un contrato de inyección a la red de distribución en su calidad de generador residencial distribuido, pues en tal caso la propiedad del equipamiento (el medidor, por ejemplo) es negociable, vid art. 149 bis LGSE.

${ }^{32}$ Art. $19 \mathrm{~N}^{\circ} 24 \mathrm{CPR}$.

${ }^{33}$ DL 2.186, 1978.

${ }^{34}$ Seguel Lizana, Pedro, “Análisis contemporáneo de la institución jurídica de la expropiación”, Universidad Andrés Bello, Santiago, 2013, pp. 1-50, disponible en línea: http://repositorio.unab.cl/xmlui/bitstream/handle/ ria/1355/Seguel_PA_An $\%$ C3\%A1ilisis $\% 20$ contemporaneo $\% 20 \mathrm{de} \% 201 \mathrm{a} \% 20$ instituci $\% \mathrm{C} 3 \% \mathrm{~B} 3 \mathrm{n} \_2013$. 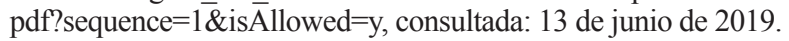

${ }^{35}$ García Oviedo, Carlos, Derecho Administrativo, E.I.S.A. Madrid, 1957, 6 a ed., p. 443.
} 
medida en los parámetros que la Constitución prevé.

En ese sentido, el acto público despojatorio de hecho amparado por la Ley 21.076 -o en otros términos, el cambio de equipos por parte del concesionario de servicio público de distribución- configura un acto ilegal tanto por no reunir las condiciones de una ley especial explícita que autorice una expropiación, como por ser contrario a las disposiciones generales del DL 2.186 sobre la materia (falta de ley que la autorice); e inconstitucional por falta de causa (limitaciones que deriven de su función social) e inconcurrencia de sus parámetros (interés general y seguridad nacional, utilidad y salubridad públicas y/o conservación del patrimonio ambiental) o requisitos (indemnización expropiatoria y pago previo).

Más aún, como se adelantó, se aprecia en la Ley $\mathrm{N}^{0} 21.076$ una sensible desconexión formal entre el título conferido a la ley y el fondo de su articulado permanente. Tanto como el título apunta a concitar adhesión popular (y asimismo parlamentaria, al imponer una obligación de hacer sobre el monopolista, la de pagar por determinados servicios asociados a la reposición de equipos), al mismo tiempo oculta o cuando menos disimula el efecto último de su prescripción permanente (expropiación velada de los equipos reemplazados y de la facultad de adquirir el dominio del equipo de reemplazo).

Por otra parte, en cuanto al fondo, la idea original de imponer a las distribuidoras una obligación permanente y general de pago por solventar servicios asociados a reponer ciertas instalaciones eléctricas (empalmes y medidores) en casos de fuerza mayor, mutó en una obligación eventual y meramente residual para casos extremadamente restrictivos (estado de excepción constitucional decretado, por catástrofe), contenida en disposiciones simplemente transitorias. ${ }^{36}$ Mientras, el articulado permanente lo que hizo -en verdad- fue modificar completamente la estructura de la red de distribución eléctrica, el régimen de propiedad (y de responsabilidad) tradicional sobre tales instalaciones y, aún más, introducir la forma de remunerar las instalaciones nuevas y repuestas por vía tarifaria (ergo de cargo del usuario), de una manera permanente. ${ }^{37}$

\footnotetext{
${ }^{36}$ Art. $1^{\circ}$ transitorio, inc. $2^{\circ}$, Ley $\mathrm{N}^{\circ} 21.076,2018$.

${ }^{37}$ En la Comisión de Minería y Energía del Senado, como impulsores de la idea de fondo de cambiar la estructura de la red de distribución ampliándola hasta abarcar los medidores y con ello modificar el régimen de propiedad tradicional de estos equipos (en lo que respecta a usuarios -hasta entoncespropietarios de medidores o empalmes), aparecen el Ministro de Energía (Sr. Andrés Rebolledo), la subsecretaria de la misma cartera (Sra. Jimena Jara) y el secretario ejecutivo de la Comisión Nacional
} 
Todo esto pudo ser posible porque -extrañamente- ${ }^{38}$ no surgió en su discusión en el Congreso cuestión alguna sobre constitucionalidad que desembocare en revisión por el Tribunal Constitucional; y por otro lado porque, no conteniendo el proyecto normas de carácter orgánico constitucional o quorum calificado, resultó exento del control preventivo por ese mismo Tribunal.

\subsection{Contravención al art. $19 N^{\circ} 23$ de la CPR}

La Constitución asegura a todas las personas: "la libertad para adquirir el dominio de toda clase de bienes, excepto aquellos que la naturaleza ha hecho comunes a todos los hombres o que deban pertenecer a la Nación toda y la ley lo declare así (...) Una ley de quórum calificado y cuando así lo exija el interés nacional puede establecer limitaciones o requisitos para la adquisición del dominio de algunos bienes". ${ }^{39}$

Para determinar la forma en que se produce la infracción de este precepto constitucional, primeramente, debemos delimitar el alcance de la infracción en relación con su objeto: no toda libertad para adquirir el dominio de medidores y empalmes ha sido afectada por la Ley $\mathrm{N}^{\circ} 21.076$, pues sabemos que aquellas instalaciones vinculadas a suministros de energía no concesibles escapan a su ámbito de aplicación. ${ }^{40}$ Tampoco la de los medidores de usuarios residenciales que ya posean equipos de generación distribuida e inyecten a la red a través de empalmes, pues a su respecto regirá un contrato con menciones específicas sobre la propiedad de las instalaciones.

En segundo término, deslindemos una vez más dicho alcance -esta vez- en el plano subjetivo. Aquí, específicamente, la libertad afectada es la de adquirir el dominio de equipos eléctricos (empalmes o medidores) de reemplazo o "inteligentes" por parte de aquellos que: 1. soliciten conexión a la red de SPED por primera vez; o, 2. la de aquellos que ya cuenten con el SPED al 27 de febrero de 2018 pero no sean generadores residenciales, es

\footnotetext{
de Energía de la época (Sr. Andrés Romero). La iniciativa terminó contando con el voto unánime de los congresistas y el beneplácito de los incumbentes.

${ }^{38} \mathrm{O}$ quizá no tan extrañamente, dada la celeridad del proceso de su tramitación en el Senado.

${ }^{39}$ Art. $19 \mathrm{~N}^{\circ} 23, \mathrm{CPR}$.

${ }^{40}$ Por ejemplo, los casos del art. 8 y las excepciones al SPED contenidas en los numerales del art. 16, ambos de la LGSE.
} 
decir -no casualmente- la amplia mayoría de la población usuaria. ${ }^{41}$

En virtud de la Ley $\mathrm{N}^{\circ} 21.076$ ninguno de estos usuarios, potenciales o actuales, está habilitado para adquirir el dominio de esas instalaciones en tanto desee conectarlas a la red de distribución. Naturalmente, es de la esencia de un aparato eléctrico de conexión (empalme) o de medición (medidor) estar conectado a una red; de otra forma, no se entiende que alguien quisiera adquirirles.

De la misma forma, querer ser dueño de alguno de estos equipos tiene ventajas concretas. Por ejemplo, cuando las empresas son dueñas de esos equipos, están habilitadas para cobrar un arriendo a sus clientes (que es un servicio asociado a la distribución eléctrica, tarifado, que no constituye

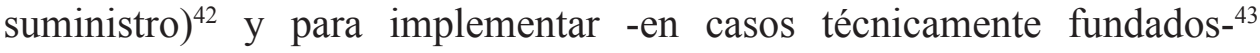
cambios de ellos (cambio o reemplazo de medidor, ejecución o instalación de empalmes, instalación o retiro de medidor, retiro o desmantelamiento de empalmes, etc.) por propia iniciativa, sin necesitar el concurso de voluntad del cliente. Por otro lado, cuando es el cliente el dueño de los equipos, por razones obvias un cobro por arriendo es improcedente y la implementación de cambios requeridos por las compañías distribuidoras necesita el consentimiento del cliente.

Adicionalmente, los SMMC, aparatos llamados "inteligentes", poseen múltiples nuevas funcionalidades como sincronización en línea, bidireccionalidad, gestión de datos, programación remota, discriminación horaria (ergo diferenciación tarifaria), etc., muchas de las cuales no sólo complementan, sino que hacen posible la configuración de la "red inteligente". Actualmente, la relevancia de los equipos de medición de suministro eléctrico se asienta sobre el ingente valor económico de los datos (de consumo, por ejemplo) asociados a ellos, así como en el de las oportunidades de negocio derivadas de su recolección, gestión y transferencia. De todo lo cual resulta que no sólo se ha limitado la posibilidad de adquirir el dominio de los SMMC nuevos, sino que además se ha coartado una oportunidad de negocio para las personas al impedírseles disponer de datos cuyo dominio, previo a la

\footnotetext{
${ }^{41}$ Aproximadamente, 6.5 millones de clientes.

${ }^{42}$ Servicio de arriendo de empalme (art. $1^{\circ}$, I.2., letra B) y servicio de arriendo de medidor (art. $1^{\circ}$, I.2, letra C), ambos del DS 197, 2009, del Ministerio de Economía.

${ }^{43}$ El art. $1^{\circ}$, I.2., letra F del DS 197, 2009, del Ministerio de Economía, prescribe que el servicio de cambio o reemplazo de medidor puede ser prestado también "a requerimiento de la distribuidora ante situaciones que impidan la correcta medida [medición] y que sean debidamente fundadas y comprobadas técnicamente".
} 
norma que nos ocupa, les hubiera correspondido naturalmente en el marco de gestión de su demanda.

En resumen, cuando impide a los usuarios ya determinados ser dueños de empalmes y medidores, lo que hace el art. 139 bis de la LGSE -en el fondoes determinar que dicha "red inteligente" y la información (data) asociada sólo pueda pertenecer a las empresas concesionarias de distribución.

\section{EFECTOS JURÍDICO-ECONÓMICOS COLATERALES DE LA INTRODUCCIÓN DEL ART. 139 BIS DE LA LGSE}

\section{Potestad de arbitraje público del art. 142 de la LGSE}

Hasta antes de la vigencia del art. 139 bis, los concesionarios podían requerir -por propia iniciativa- cambios en el sistema de suministro, pero esta pretensión no era absoluta ni mucho menos gratis.

No era absoluta porque necesariamente requería la concurrencia de voluntad del usuario; si no contaba con ella, el concesionario no podía implementar cambios en el sistema de suministro, lo que -ilustrativamenteincluía la adaptación de motores y aparatos en uso por los clientes.

Y tampoco era una pretensión exenta de costo para la distribuidora, porque los cambios o adaptaciones corrían por su cuenta y debía compensar a sus clientes (propietarios de los equipos involucrados en el cambio).

Sin embargo, lo más relevante en este marco normativo previo al art. 139 bis era que, de no existir acuerdo entre cliente y concesionario acerca de la necesidad del cambio en el sistema de suministro, o en el monto de la compensación pertinente a las adaptaciones que fueren necesarias para su implementación, el art. 142 de la LGSE dispone que la cuestión sería resuelta por la SEC.

Ahora bien, cuando el art. 139 bis reconfigura la red de distribución eléctrica para incorporar empalmes y medidores de los clientes, cambiando la titularidad de su dominio desde éstos a los concesionarios, entra en conflicto con -y pone en entredicho- la vigencia del art. 142 LGSE en lo que atañe a los suministros que constituyen SPED.

En efecto y a partir de entonces, ha operado la derogación tácita de la potestad pública de arbitraje radicada en la SEC motivada por cambios en el sistema de suministro requeridos por la concesionaria. En lo sucesivo, los cambios en el sistema que atañan a los equipos no podrán ser controvertidos 
por los clientes, pues los que pretenda el concesionario ya no estarán amparados en su simple deseo (iniciativa), sino que directamente en una norma legal que amplió la red de distribución y le traspasó la titularidad de su dominio.

Aquella era una función de adjudicación importante entre un proveedor monopólico y sus clientes, con respecto a un servicio público (el de distribución eléctrica), radicada en un organismo administrativo fiscalizador y supuestamente imparcial que debía equilibrar los intereses y las pretensiones de las partes en desacuerdo y con un desnivel evidente en su poder de mercado.

Más allá de configurar una potestad pública, con todo lo que ello apareja; la capacidad de una autoridad pública de mediar en estos conflictos por cambio del sistema de suministro revestía una doble importancia: por una parte, la de adjudicar en cuestiones técnicas de complejidad y en las que el usuario común podría ver aún más mermada su capacidad de defensa o de negociación en la vertiente simplemente compensatoria del problema; pero, por otro parte, la función resultaba crítica en la capacidad del Estado de llevar adelante políticas públicas de interés general o bien común, como por ejemplo, políticas basadas en la gestión de demanda o generación distribuida (smart metering/net billing) que requieren la implementación de tecnologías compatibles.

\section{Posibilidad de constituir sub-sistemas de distribución}

Antes del art. 139 bis, la norma técnica sobre medidores ${ }^{44}$ y la de instalaciones de consumo en baja tensión ${ }^{45}$ discurrían sobre la idea de una red de distribución que -en términos generales- sólo alcanzaba a los empalmes de propiedad de las distribuidoras concesionarias, la red llegaba hasta este punto; y, más allá, la propiedad de los equipos y la responsabilidad sobre los mismos recaía en los usuarios.

La reconfiguración de la estructura de la red de distribución en virtud del art. 139 bis de la LGSE provocó efectos colaterales no advertidos en el marco técnico reglamentario. Uno de ellos atañe a los sub-sistemas de distribución contemplados en la Norma Técnica NCh. 4/2003.

La NCh. 4/2003 denomina como subsistema de distribución a "una

\footnotetext{
${ }^{44}$ Norma Técnica sobre medidores (NSEG 3En71).

${ }^{45}$ Norma Técnica $N^{\circ}$ 4/2003 sobre instalaciones de consumo en baja tensión.
} 
red eléctrica de distribución construida dentro de los límites de la propiedad del edificio o condominio, administrada y mantenida por la comunidad, sus representantes o quienes ella designe, cuya finalidad será proveer de energía eléctrica a cada uno de sus integrantes, en forma independiente del control de la Empresa Eléctrica concesionaria de la zona". ${ }^{46} \mathrm{Y}$ de acuerdo con ella, "cualquier comunidad constituida por los habitantes o usuarios de edificios de altura, condominios o similares podrá optar a la alternativa de obtener energía eléctrica desde un subsistema de distribución" ${ }^{47}$

Como es fácil apreciar, la posibilidad de que existan estos subsistemas es favorecer el aprovechamiento -por los clientes usuarios finales organizadosde las ventajas económicas que supone negociar la adquisición de bloques de energía.

Desde el análisis económico del Derecho, el derecho colectivo establecido por la norma técnica supone la autonomía de un grupo intermedio que no sólo es capaz de organizarse para efectuar estudios de costo y calidad de servicio alternativos y más eficientes económicamente que los propuestos por el monopolista; sino que, también, resulta empoderado para administrar el subsistema y mantener el suministro individual, e incluso -esto es lo verdaderamente importante- hacerlo con total independencia del control del concesionario de distribución. ${ }^{48}$

Si alguna duda podía surgir acerca de esa independencia vital, la NCh. 4/2003 se encargaba claramente de disiparla al disponer que las concesionarias no podrán oponerse a la constitución de un subsistema de distribución que haya cumplido todas sus exigencias. ${ }^{49} \mathrm{Y}$ más aún, los subsistemas de distribución debían regular su accionar mediante un contrato privado establecido entre sus integrantes y según un reglamento interno acorde a la legislación vigente..$^{50}$

Naturalmente, para que tal opción fuese real, el subsistema de distribución debía ser considerado un servicio único; y por ello la NCh. 4/2003 establecía -para todos los efectos- que las obligaciones, derechos y deberes de la empresa de distribución debían referirse sólo con respecto al punto de empalme.

\footnotetext{
${ }^{46}$ Art. 5.2.2 NCh. 4/2003.

${ }^{47}$ Art. 5.2.1 NCh. 4/2003

${ }^{48}$ Art. 5.2.2 NCh. 4/2003.

${ }^{49}$ Art. 5.2.8 NCh. 4/2003.

${ }^{50}$ Art. 5.2.4 NCh. 4/2003.
} 
Pues bien, tras el art. 139 bis los empalmes y medidores siguen siendo instalaciones eléctricas de consumo en baja tensión y, como tales, siguen sujetos a las normas técnicas en la materia. Pero, como la red de distribución se amplió hasta los medidores y se modificó el régimen de propiedad de estas instalaciones, resulta que el derecho colectivo a constituir, administrar y mantener un subsistema de distribución con independencia del concesionario, ha resultado tácitamente derogado desde la entrada en vigencia del art. 139 bis de la LGSE.

Se podría argüir sed contra que el artículo 11 del reciente nuevo Reglamento de Seguridad de las Instalaciones de Consumo Eléctrico, ${ }^{51}$ trata la constitución de subsistemas de distribución, lo que descartaría su imposibilidad. Sin embargo, es necesario plantear que la mera existencia de una norma reglamentaria que deriva de otra legal sindicada inconstitucional, ni afirma su propia legitimidad ni menos vuelve constitucional a la norma legal de la cual emana. Dicho de otro modo, si la tesis de inconstitucionalidad del art. 139 bis LGSE es siquiera plausible, el juicio sobre la validez de normas (reglamentaria, en este caso) debe suspenderse. Y aún si no -como se concluirá- el problema revierte al de independencia de los colectivos intermedios al control del distribuidor.

En relación con el planteamiento anterior resulta útil, además, analizar con detenimiento la redacción del novel artículo 11. Resulta muy interesante constatar que, de manera muy apropiada pero conveniente también al interés de las distribuidoras, dicha norma per se no prejuzga sobre la titularidad del dominio del subsistema de distribución.

Ello es así porque, de lo que realmente se ocupa el artículo 11 es de regular una alternativa o derecho de opción de suministro (a través de un subsistema de distribución de propietario innominado). Desde el punto de vista del análisis jurídico-económico: regula el acceso abierto o la no existencia de barreras de entrada a un tipo específico de suministro eléctrico; pero ciertamente no la propiedad (ni la extensión) de la red (que, por efecto del art. 139 bis de la LGSE hoy engloba a tal subsistema de distribución). Dicho de otro modo, el artículo 11 de marras trata del acceso; ${ }^{52}$ pero es el art. 139 bis el que establece quién es el dueño de las instalaciones del subsistema hasta el empalme y el medidor.

${ }^{51}$ D.S. No $8 / 2020$, Ministerio de Energía.

${ }^{52}$ Por cierto, junto a otras cosas más, como el retiro, la seguridad, la operación y el mantenimiento de las instalaciones. 
Como bien se sabe -o al menos así era hasta la introducción del art. 139 bis según plantea esta investigación- los subsistemas de distribución se constituyen sobre la base de contratos privados, en los cuales se pactaba su accionar y se determinaba la propiedad y cargo de costo de las instalaciones necesarias, lo que jurídico-económicamente hablando se justificaba, en pro del equilibrio de poder negociador entre los intervinientes.

Sin embargo, podría argüirse que el art. 11 del D.S. No 8/2020 conspira $a b$ initio contra el acuerdo colectivo para "optar por la alternativa de obtener energía eléctrica desde un subsistema de distribución”; o lo que es lo mismo, contra el interés de contrapesar el poder de mercado del monopolista, cuando permite la renuncia al subsistema de distribución. En efecto, por una parte, sabemos que el suministro resulta esencial para los interesados (ya individual y/o colectivamente); y por otra, no toma mucho esfuerzo imaginar la postura de las distribuidoras quienes, sin duda, esgrimirán la titularidad dominical que les acuerda el art. 139 bis de la LGSE, al momento de pactar la constitución de alguno de estos subsistemas de distribución.

Todas estas reflexiones lo que hacen, en verdad, es revelar la íntima conexión entre el efecto jurídico-económico del art. 139 bis LGSE (según describe la tesis principal de esta investigación) y el mismo tipo de efecto del reciente art. 11 del D.S. No 8/2020.

A modo de síntesis: la mera existencia de una norma reglamentaria (art. $11 \mathrm{D}, \mathrm{S} . \mathrm{N}^{\mathrm{o}} 8 / 2020$ ) sobre la materia (subsistemas de distribución) no obsta a (ni menos aún subsana) la inconstitucionalidad de la norma legal de la cual procede; o de cuya interrelación, se produce la afectación grave de un objetivo jurídico-económico de interés público (el contrapeso al poder de mercado monopólico) que es consustancial a la posibilidad reconocida a grupos intermedios (formados por los habitantes o usuarios de edificios, condominios o similares), de constituir un subsistema de distribución que no altere el régimen de propiedad de los equipos eléctricos (como el medidor).En resumen, dicha norma lesiona el derecho colectivo reconocido a un grupo intermedio -con un interés económico contrapuesto al de los concesionarios- y que les confería (al poder ser dueños de los equipos) un contrapeso a su enorme poder de mercado. En otras palabras, en vez de propender a la defensa de los consumidores potenciando dichos contrapesos frente a un proveedor monopólico, el art. 139 bis -y a la saga el art. 11 del D.S. $N^{\circ} 8 / 2020$ - hizo todo lo contrario: eliminó el contrapeso y fortaleció la posición del monopolista. 
La LGSE dispone que, en su zona de concesión, las empresas distribuidoras están obligadas a proporcionar el servicio de distribución eléctrica -que es uno público- a quien lo solicite. ${ }^{53}$

Pero, cuando un usuario o cliente solicitaba el servicio por primera vez, y para conectarle a la red de distribución eran necesarias obras de extensión de instalaciones eléctricas hasta el punto de empalme del peticionario, ${ }^{54}$ la LGSE permitía a los concesionarios exigir a aquel "aportes de financiamiento reembolsables" (en adelante, AFR) para la ejecución de las obras requeridas hasta determinados montos máximos que podía determinar la misma empresa y aplicarlos previa difusión en un periódico de circulación nacional. ${ }^{55}$ Los AFR podían adoptar dos formas: 1 . El valor del proyecto de extensión de obras (hasta el empalme) determinado y aprobado por la concesionaria y cuya ejecución asumía el peticionario; y 2. El valor de las obras determinado por la empresa, cuya ejecución asumía, una vez que el peticionario asegurase su financiamiento. ${ }^{56}$

Los AFR resultaban especialmente útiles no sólo para aquellos potenciales usuarios en regiones remotas o aisladas con dificultad de conexión, sino también para todos aquellos otros que se encontraban -en general- fuera de la zona de concesión, pero con la posibilidad de conectarse a las instalaciones de una concesionaria de distribución mediante líneas propias o de terceros. Naturalmente, el costo financiero de los AFR recaía inequívocamente en los peticionarios interesados, lo que tenía lógica, al demandar costos de distribución ajenos a la zona concesionada.

Sin embargo, como sabemos, el art. 139 bis LGSE amplió la red de distribución eléctrica hasta los medidores y traspasó su dominio a las concesionarias. Es interesante notar los efectos de esta medida en las hipótesis previas de AFR, por una parte; y en la contribución al financiamiento de sus obras, por la otra.

En cuanto a las hipótesis de AFR ya vimos una: la extensión de instalaciones hasta el empalme en primera solicitud de servicio; pero también son posibles AFR para ampliar la potencia conectada y/o la

\footnotetext{
${ }^{53}$ Art. 125 LGSE.

${ }^{54}$ Art. 127 LGSE.

${ }^{55}$ Art. 126 LGSE.

${ }^{56}$ Art. 127 LGSE.
} 
capacidad requerida en distribución, evidentemente, cuando ya se cuenta con el servicio.

$\mathrm{Si}$ las expresiones empleadas por el art. $1^{\circ}$ transitorio de la Ley $\mathrm{N}^{\circ} 21.076$ sobre "cambio" de instalaciones (esto es suponiendo unas ya existentes, en los términos analizados) no dejaren en claro que la hipótesis de AFR por primera solicitud de servicio no está incluida, la modificación del régimen de propiedad de equipos y de estructura de la red de distribución introducida por el art. 139 bis, hubiera resultado en una ventaja superlativa para los usuarios de zonas aisladas o remotas quienes habrían tenido derecho a conectarse a la red de suministro público eléctrico sin costo alguno para ellos, o sea sin la necesidad de convenir un AFR, ${ }^{57}$ pues la concesionaria ha pasado a ser la dueña y responsable de las instalaciones eléctricas de la red hasta los medidores. Naturalmente, este ventajoso escenario para los usuarios potenciales primerizos fue convenientemente excluido del ámbito de aplicación de la Ley $\mathrm{N}^{\circ} 21.076$.

Por otra parte, en la hipótesis siguiente, sobre ampliación de potencia conectada o capacidad de distribución requerida y que supone usuarios que ya cuentan con el servicio y no son generadores residenciales, ${ }^{58}$ dos supuestos son posibles: a) Si las instalaciones ya son de propiedad de la concesionaria, la petición de ampliar su potencia o su capacidad impide convenir un AFR y deja la ejecución de las ampliaciones al libre arbitrio jurídico de la empresa distribuidora, a quien -por operación del art. 139 bis- correspondería asumir dicha ejecución a su entero costo, algo que -económicamente- es plausible presumir que no tendrá incentivo alguno de hacer si finalmente no puede traspasar dicho costo al usuario vía "servicios asociados", por ejemplo; y, b) Si las instalaciones pertenecen aún a particulares, la solicitud de ampliación (de potencia conectada o capacidad instalada) y la ejecución de las obras requeridas podría configurar el "cambio" de instalaciones del art. $1^{\circ}$ transitorio y que hace operativo la normativa permanente del art. 139 bis de la LGSE, ergo, el cambio en la titularidad de su dominio a favor de la distribuidora. $^{59}$

\footnotetext{
${ }^{57}$ Convenir, claro está, resulta un eufemismo porque los AFR -en verdad- se formalizan mediante un contrato de adhesión.

${ }^{58}$ Ello porque si estos usuarios fueren generadores residenciales conectados, que inyecten excedentes a la red de distribución a través de los empalmes, estas inyecciones han de regirse por un contrato con las concesionarias de SPED el que -entre otras menciones mínimas- debe abordar la propiedad del equipo medidor. Art. 149 bis inc. 11 LGSE.

${ }^{59}$ De manera similar, el traspaso de titularidad del dominio podría configurarse vía el ya explicado
} 
En resumen, si bien el art. 139 bis no innova en la hipótesis de los AFR por extensión de instalaciones hasta el empalme en la primera solicitud de servicio, ni en la de AFR por ampliación de potencia conectada o capacidad en distribución de instalaciones de la concesionaria; sí abroga la posibilidad de los AFR cuando se pida tales ampliaciones de potencia o capacidad por usuarios dueños de los equipos, específicamente. Y en este caso, aún más, la ejecución de lo pedido por parte de la distribuidora podría gatillar el cambio de dominio de los equipos, por efecto del art. 139 bis de la LGSE.

\section{INCLUSIÓN TARIFARIA DEL FINANCIAMIENTO DEL COSTO DE EQUIPOS}

Las políticas públicas generales y de largo plazo que impulsan el derecho de los usuarios a vender sus excedentes de energía al sistema, se complementan con aquellas que ponen de relieve la gestión de demanda por los mismos usuarios.

En efecto, si a la generación distribuida se suma el control de la propia demanda, los excedentes disponibles deberían potenciarse. Resulta evidente que para ambas funciones -generación y consumo- la medición es crucial. Y si añadimos las nuevas funcionalidades de los equipos medidores de última generación, podemos fácilmente dimensionar la relevancia de los cambios introducidos por la Ley $\mathrm{N}^{\circ} 21.076$.

Pero es respecto de su financiamiento donde la -ya álgida- polémica sobre el recambio de medidores llega a su clímax; porque una cosa es para qué sirven y una muy distinta es cuánto cuestan y quién debe pagar por los medidores y por sus servicios asociados. Resultaba razonable que, mientras el dominio de los equipos o empalmes podían recaer sobre clientes o concesionarios (de acuerdo al régimen de titularidad correspondiente) y la contribución a su costo no estaba regulada, cada quien se hacía cargo de sus costos. Pero, tras el art. 139 bis de la LGSE, que hace dueñas de estas instalaciones a las concesionarias, el costo financiero de los nuevos aparatos de recambio resulta solventado nada más y nada menos que por el usuario, al disponer la ley que se le incluya en las fórmulas tarifarias reguladas por decreto, según explicaremos a continuación.

En el sector energético, tanto la transmisión como la distribución 
eléctrica constituyen monopolios naturales y, por ende, el Estado regula las tarifas para contrarrestar los beneficios extraordinarios del monopolista y posibilitar que los usuarios obtengan el suministro a precios lo más cercanos posibles a los que se obtendrían en condiciones de competencia perfecta. Mediante los procesos tarifarios, el Estado considera las inversiones necesarias que las empresas proveedoras se obligan a ejecutar, para suministrar el servicio con la calidad determinada por el Estado, y establecen límites a la rentabilidad de las mismas.

Si el concesionario cumple sus obligaciones y presta el servicio con propiedad, ${ }^{60}$ tiene derecho a recibir la contraprestación pactada.$^{61}$ En general, esta contraprestación o tarifa eléctrica final contiene cargos asociados clasificables en dos categorías: a) cargos a nivel generación-transporte; y b) cargos a nivel de distribución.

Los cargos del primer grupo corresponden al "precio de nudo", definido para toda subestación eléctrica del sistema de transmisión desde las cuales se efectúe suministro a clientes regulados y que consta de dos componentes: energía y potencia. Con respecto al segundo grupo de cargos, a nivel de distribución, ellos contemplan: los precios de nudo en el punto de conexión a las instalaciones de distribución, cargos únicos por uso del sistema de transmisión nacional, ${ }^{62}$ y el valor agregado de costos de distribución (VAD) vigente en la zona de concesión. ${ }^{63}$

Con más precisión aún, el art. 182 de la LGSE establece que el VAD considera costos fijos de administración, pérdidas medias de distribución tanto en potencia como en energía y costos estándares de inversión,

\footnotetext{
${ }^{60}$ Esto es, en las condiciones técnicas y de seguridad que se establezcan.

${ }^{61}$ La contraprestación que formó parte de las bases de la licitación pública respectiva y que se plasmó, finalmente, en el contrato de concesión.

${ }^{62}$ Cargo por uso del sistema de transmisión nacional, cargo por uso de sistemas de transmisión zonal y cargo por uso de sistemas de transmisión dedicada contemplados en el art. 115 de la LGSE.; cargo único por uso de sistemas de transmisión para polos de desarrollo del art. $116 \mathrm{y}$ cargo por servicio público del art. 212-13 de la misma norma.

${ }^{63}$ Art. 181 y ss. de la LGSE. El "valor agregado de distribución" (VAD) considera todos los costos en que incurre una distribuidora por prestar el SPED, los que son incluidos posteriormente en las tarifas de los clientes finales. De acuerdo al art. 182, el VAD se corresponde al costo medio de una empresa modelo teórica (eficiente tanto en política de inversiones como en gestión) operando en el país y que considera costos fijos por gastos administrativos, pérdidas medias de distribución de potencia y energía y costos estándares de inversión, mantención y operación; calculados para áreas de distribución típicas sobre la base de un estudio de costos encargado por la CNE a una consultora; el que puede ser contrastado por otro encargado por la o las concesionarias. El VAD es fijado cada cuatro años por el Ministerio de Energía, previo informe técnico de la CNE
} 
mantención y operación. A su vez, los costos de inversión son anualizados, considerando el "valor nuevo de reemplazo" (VNR), de instalaciones adaptadas a la demanda.

De acuerdo con la Ley No 21.076, el empalme y el medidor pasarán a ser parte de la red de distribución y, por tanto, serán de propiedad de quien preste el SPED. Así, todo nuevo equipo (empalme o medidor) que se instale será de propiedad de la distribuidora y los costos asociados serán reconocidos como "costos estándares de inversión, mantención y operación" asociados al ejercicio de distribución, por lo tanto, debiendo ser incluidos en tarifa.

Por otra parte, el valor de los servicios que no constituyen suministro del $\mathrm{N}^{\circ} 4$ del art. 147 de la LGSE (aquellos relativos al cambio de equipos del DS 197) se determina de acuerdo con los estudios de costos a que alude el art. 183 de la LGSE; pero, según el art. 184 de la misma norma, por regla general no forman parte del VAD. Tras la modificación introducida por la llamada Ley de Equidad Tarifaria, ${ }^{64}$ la excepción es el proceso de fijación de tarifas de suministro de distribución, contemplada precisamente en el inciso cuarto del mismo art. $184 .{ }^{65}$

Con respecto a la remuneración de servicios asociados, como mantención y reposición, si los medidores corresponden a los nuevos SMMC que establece la normativa, los costos asociados a su instalación, mantención, recambio o reconfiguración deberán ser incluidos en tarifas según lo que determine el proceso tarifario. ${ }^{66}$ En otros términos, los servicios asociados sí tienen un componente tarifario en la distribución, continúan sujetos a regulación de precios y conllevan la obligación de prestarlos como servicio público. Hoy en día, los precios de ocho servicios asociados relacionados

${ }^{64}$ Ley $\mathrm{N}^{\circ} 20.928,2016$, que introdujo el inciso cuarto y final al art. 184 LGSE.

${ }^{65}$ Las tarifas de suministro de electricidad son fijadas con fórmulas de cálculo establecidas cada cuatro años mediante un decreto tarifario. Éste contempla distintas opciones tarifarias a las que puede optar un usuario, por un plazo mínimo de un año, dependiendo de su conveniencia y tipo de consumo. Las opciones tarifarias se estructuran según diversas formas de consumo: energía, potencia máxima leída o contratada, y potencia leída o contratada horariamente, para dos categorías de clientes: en alta tensión (AT) y en baja tensión (BT).

${ }^{66}$ Mientras, costos con respecto a medidores y/o empalmes tales como los de instalación, mantención, reconfiguración, arriendo (de empalme o de medidor, cuando corresponda), aumento de capacidad de empalme, cambio o reemplazo de medidor, entre otros, están regulados por el decreto tarifario que fija los precios de servicios no consistentes en suministros de energía asociados a la distribución eléctrica, que aparecen en la cuenta final separadamente de la tarifa eléctrica. 
con empalmes y medidores ${ }^{67}$ están regulados tarifariamente por el DS 11T, ${ }^{68}$ modificado por el DS 5T, ${ }^{69}$ vigente para el cuatrienio 2017-2020.

El lector recordará que advertimos que era notable que el art. $1^{\circ}$ transitorio nada dijera del financiamiento de los equipos de reemplazo y que sólo aludiera al de los servicios asociados al cambio. Pues bien, aunque notable, ello no tiene nada de casual ya que, por una parte, el art. $2^{\circ}$ transitorio permitió modificar los decretos tarifarios para incorporar los "mayores costos" en la prestación del servicio público eléctrico, asociados a la ley y a la normativa técnica; y por otra, esta norma transitoria sintoniza a la perfección con la frase del articulado permanente que también involucra a los decretos tarifarios en cuanto a incluir en sus fórmulas "la remuneración de estas instalaciones".

En términos simples y por increíble que parezca, la ley dispuso que los usuarios regulados paguen el costo de medidores y empalmes que nunca serán suyos (y, ergo, cuyas nuevas funcionalidades tampoco podrán controlar o aprovechar). Contribución a la deuda nada despreciable ya que el financiamiento estimado del recambio asciende a USD\$1.000 millones que, en el caso de algunas distribuidoras, ya comenzaron a cobrar a sus usuarios vía partida "servicios asociados" en las cuentas de luz, ${ }^{70}$ desde septiembre de 2018.

Por otra parte, ya vimos que el financiamiento del costo de los servicios asociados a la distribución que no constituyen suministro también se vinculan con los decretos tarifarios. ${ }^{71}$

\footnotetext{
${ }^{67}$ Los servicios asociados son: 1. Retiro y reposición de empalme, 2. Arriendo de medidor, 3. Cambio o reemplazo de medidor, 4. Conexión y desconexión de empalme a la red, 5. Ejecución o construcción de empalmes, 6. Instalación o retiro de medidores, 7. Mantenimiento de medidor de propiedad del cliente, y 8. Retiro o desmantelamiento de empalmes.

${ }^{68}$ DS 11T, de 4 de noviembre de 2016, Ministerio de Energía.

${ }^{69}$ DS 5T, de 7 de marzo de 2018, Ministerio de Energía.

${ }^{70}$ No obstante que dicha cuenta incorpore ya un componente tarifario, esto es, forme parte del proceso regulatorio de la tarifa de distribución. El valor agregado de distribución (VAD) se funda en el AVI+COMA/retiros de energía (USD/Kwh) en función de un modelo teórico de empresa (económicamente) eficiente en política de inversiones y en su gestión.

${ }^{71}$ Tal es el caso de los servicios tradicionales asociados a la distribución que no constituyen suministro y que están regulados. A fortiori, la remuneración o financiamiento del costo de eventuales nuevos servicios que tampoco constituyan suministro, pero que estén relacionados con funcionalidades nuevas de equipos o instalaciones eléctricas asociados igualmente a la distribución, también deberían ser objeto de regulación tarifaria; pues no cabe presumir simetría en el poder de mercado de clientes y empresas distribuidoras que hiciere posible una negociación equitativa, ergo, un precio de mercado para estos servicios.
} 
En resumen, la Ley $\mathrm{N}^{\circ} 21.076$ dispuso que la forma de incluir en las fórmulas tarifarias la remuneración de medidores y empalmes, así como las condiciones de aplicación de las tarifas asociadas a tales fórmulas es materia de los decretos tarifarios de los arts. 120, 184, 187 y 190 de la LGSE. En otras palabras y en último término, además de la contribución a los costos de los servicios por desmantelamiento y retiro de empalmes y medidores antiguos (ya vistos), la ley dispone que el costo financiero de la sustitución con nuevos medidores "inteligentes" es de cargo de los usuarios regulados vía tarifas.

Por las múltiples razones que anteceden, sostenemos que el art. 139 bis es inconstitucional en el fondo y, como tal, pasible de inaplicabilidad por inconstitucionalidad y/o acción de protección. Consecuencialmente, además, los actos derivados de su aplicación adolecen de nulidad administrativa y/o ilegalidad reclamable pudiendo, asimismo, ser impugnados en sede judicial mediante la acción colectiva de la ley que establece normas sobre protección de los derechos de los consumidores y/o mediante el recurso de casación en el fondo, si existiere una gestión judicial pendiente, contra una sentencia que lo habilite y en que dicha norma se estimare decisoria litis. Adicionalmente, nuestro estudio concluye en todo caso la derogación tácita de una función pública de arbitraje, la lesión a la autonomía de un grupo intermedio y la desaparición de contrapesos de los usuarios regulados al poder de mercado de las concesionarias de distribución, en cuanto monopolistas naturales.

\section{ANÁLISIS JURÍDICO-ECONÓMICO}

Vale la pena ahondar en la relevancia del bien o interés público comprometido en el servicio público de suministrar electricidad en media y baja tensión. Aunque parezca evidente, es muy pertinente recordar que el género próximo del concepto SPED es ser un servicio público; y su diferencia específica: recaer sobre la distribución de electricidad.

El carácter público del servicio se manifiesta de varias formas: por ejemplo, en que el SPED sea concesible y en que para establecer la concesión se requiera un procedimiento administrativo reglado de licitación. ${ }^{72}$

72 Art. 26 LGSE. Vid también DS N 126, de 2013, Ministerio de Energía, que modifica el DS № 4, de 2008, Ministerio de Economía, que aprueba el Reglamento sobre Licitaciones de Suministro de Energía para satisfacer el consumo de los clientes regulados de las empresas concesionarias del Servicio 
Aún más, para la LGSE, el procedimiento mismo de licitación pública de una concesión de SPED debe apuntar a cuatro objetivos explícitos: a) eficiencia económica, b) competitividad, c) seguridad, y d) diversificación. ${ }^{73}$ Todos ellos -cabe remarcarlo- relacionados con la actividad y el carácter del concesionario; y no de terceros, como los usuarios regulados.

La eficiencia económica supone la mayor provisión posible (de servicio) al menor costo (económico) del concesionario, otra vez, no de terceros (los clientes); por otra parte, una mayor competitividad es la clave cuando de formas de competencia imperfecta se trata, como en los monopolios que -precisamente- disponen del poder de traspasar sus costos económicos a terceros; la seguridad incluye no sólo la del suministro, sino también la de bienes o prestaciones anexas, como podrían ser la información o datos de consumo; y finalmente la diversificación, objetivo especialmente relevante en lo que atañe a la naciente generación distribuida, ${ }^{74}$ como objetivo de política energética.

El interés público involucrado en el SPED también infunde las obligaciones y derechos que nacen para el concesionario cuando la concesión de SPED se halla en régimen/explotación. En efecto, por una parte, el concesionario tiene la obligación de "mantener las instalaciones en buen estado (...) de acuerdo a las disposiciones reglamentarias correspondientes". ${ }^{75}$ Por otra, las formas en que una concesión de SPED puede extinguirse ex post trasuntan igualmente la relevancia del interés público comprometido en ellas, pues si el concesionario no cumple -por ejemplo- con su obligación de mantener las instalaciones en buen estado, la falta de calidad de servicio configura causal de caducidad ex post de la concesión. ${ }^{76}$

Por otra parte, vimos que si el concesionario cumple sus obligaciones y -subrogando al Estado- presta el servicio con propiedad, tiene derecho a

Público de Distribución de Energía Eléctrica (Reglamento Licitaciones de Suministro).

${ }^{73}$ Art. 131 bis LGSE.

${ }^{74}$ El objetivo de diversificación de los procesos licitatorios públicos de suministro eléctrico puede abarcar un amplio espectro, desde la generación normal y la distribuida, pasando por la bidireccionalidad de la información sobre retiros e inyecciones de los clientes regulados, hasta la evolución hacia un nuevo esquema tarifario simple.

${ }^{75}$ Art. 139 LGSE.

${ }^{76}$ Las causales de caducidad ex post de las concesiones de SPED están previstas en los arts. 41 letra a) en relación con art. 129 y en el art. 47 LGSE. Por otra parte, las concesiones de SPED pueden caducar ex ante en los casos contemplados por el art. 39 LGSE. Es pertinente recordar que las causales de caducidad son de derecho estricto y su interpretación es, por lo mismo, restrictiva. 
recibir una contraprestación pactada. Y, por otro lado, las funcionalidades que se atribuyen a los equipos de nueva generación SMMC, como los medidores inteligentes, ${ }^{77}$ posibilitan la oferta de nuevos productos y servicios asociados por parte de los concesionarios, ${ }^{78}$ cuyos costos no estarían -en principio- incorporados en el VAD (por no ser constitutivos de suministros); pero que excepcionalmente por vincularse a la distribución, y en virtud del inciso final del art. 184, deberían adquirir reconocimiento a nivel tarifario.

El gran efecto económico de la tecnología es conocido: provee y potencia el poder de mercado; esto es, precisamente, lo que define a las formas imperfectas de competencia como los monopolios. Basta considerar la capacidad de programar remotamente aumentos o reducciones de potencia, o la de configurar el consumo de acuerdo a tarifas horarias distintas, por ejemplo, para advertir que las nuevas funcionalidades de los equipos de recambio, su nueva tecnología en términos generales, implicaría cambios en el sistema de suministro que desee implementar un concesionario.

Cuando objetivos como el de eficiencia económica y competitividad de los concesionarios son menoscabados, ya por el traspaso de costos hacia terceros (tarifas) o por la imposibilidad de contrarrestar el poder de mercado de proveedores monopólicos (sub-sistemas de distribución); o cuando se impide que los objetivos de seguridad y diversificación sean alcanzados, por ejemplo, haciendo desaparecer el incentivo de particulares para gestionar su propia generación y consumo, afectando la propiedad de los equipos e impidiendo así el uso de aplicaciones de gestión como Watty, Sense, o Solarix, ${ }^{79}$ es evidente -desde el punto de vista del análisis económico- que se resiente el beneficio marginal de la sociedad en su conjunto.

Pero, cuando aquel pernicioso efecto es causado -precisamente- por una modificación legal que afecta estructuras básicas de mercado (propiedad individual, incentivos) y funciones públicas (de adjudicación, regulación de

\footnotetext{
${ }^{77}$ Por ejemplo, información en línea de clientes desconectados; medición remota de energía, potencia activa y reactiva, voltaje y corriente y potencia media; acceso y lectura remota de consumo; programación remota para configurar consumos de acuerdo a diversas tarifas y variaciones de potencia (aumentos o reducción); información de curvas de carga y consumo; información para programar de manera remota actividades de corte y reposición de suministro; medición remota bidireccional, esto es, de la energía suministrada por el concesionario al cliente y de la que éste último pueda aportar a la red mediante sistemas de generación propios interconectados.

${ }^{78}$ Carta GRYP-023/2017, de CHILQUINTA y Carta Ger. Gen. Nº 119/2017, de ENEL, ambas dirigidas a la Comisión Nacional de Energía (CNE) y citadas en Comisión NACIONAL de Energía, cit. (n.24).

${ }^{79}$ Aplicaciones de gestión de demanda como Watty, Sense y Solarix entre otras, requieren acceso a los datos y control sobre los equipos eléctricos asociados al suministro de distribución.
} 
precios y/o utilidades, etc.) de las que precisamente cabía esperar un efecto contrario, esto es, ser capaz o al menos intentar incorporar equilibrio en el natural y asimétrico poder de mercado entre los incumbentes, o propender a una redistribución de las utilidades o los costos, o equiparar el acceso a la información o mejorar su transparencia, o hacer posible la gestión independiente de las funciones de generación y consumo de energía que fomentan otras políticas públicas, de todo ello no resulta sino un tradeoff económico favorable a los intereses de empresas distribuidoras y en desmedro de los usuarios regulados.

Finalmente, todo esto importa porque en el SPED se trata con la prestación (no transacción) de una actividad inmaterial (servicio) del Estado o de un privado que le subroga (pública), cuya disponibilidad no depende de la interacción libre de oferta y demanda (de un bien material determinado, un commodity), por la cual recibe una contraprestación cuyo precio de equilibrio no se alcanzaría en condiciones de libre competencia, sino que es determinado por intervención regulatoria (tarifas). De esa forma, los usuarios pagan por el SPED una tarifa teóricamente eficiente desde el punto de vista económico, siendo el Estado quien debe fiscalizar el cumplimiento de las exigencias de seguridad y calidad de suministro; y las empresas quienes deben realizar las inversiones necesarias para prestarlo bajo tales parámetros, y con una rentabilidad regulada por la propia ley.

\section{CONCLUSIONES}

1.- El SPED es, antes que nada, un servicio público. En él, la consideración del interés público es un elemento de la esencia. Pero, además, es un servicio público regulado; y así se manifiesta en los objetivos del procedimiento licitatorio de suministro público, su carácter concesible, las obligaciones del concesionario y hasta en las causales de caducidad de la concesión de SPED.

2.- Esta investigación concluye que, no obstante una legalidad formal no exenta de particularidades -incongruencia entre título y fondo, entre efecto permanente y transitorio- el art. 139 bis de la LGSE, introducido por la Ley $\mathrm{N}^{\mathrm{o}} 21.076$, adolece de inconstitucionalidad de fondo por contravenir las garantías de los arts. 19 Nos. 23 y 24 de la CPR.

3.- En efecto, el art. 139 bis siendo ley común, impone veladamente la expropiación de empalmes y medidores eléctricos sin ajustarse a las 
exigencias de la Constitución para una medida de este tipo. Constituye una privación de la propiedad y del bien sobre el que recae, una expoliación del patrimonio de los usuarios dueños de tales equipos, a quienes la distribuidora requiera su cambio por razones técnicas con posterioridad al 27 de febrero de 2018, sin acto expropiatorio, ergo, sin indemnización compensatoria.

4.- El cambio de equipos -por parte del concesionario de servicio público de distribución- amparado por la Ley 21.076 configura un acto público despojatorio de hecho, y como tal, pasible de inaplicabilidad por inconstitucionalidad, al carecer de fundamento en alguno de los parámetros de la función social de la propiedad, e incumplimiento de sus requisitos, de acuerdo con el art. $93 \mathrm{~N}^{\circ} 6$ de la CPR. También las conductas derivadas de su implementación podrían ser atacables vía acción constitucional de protección, de acuerdo con el art. 20 de la CPR. Adicionalmente, los actos administrativos que anteceden o derivan del cambio son susceptibles de reclamación por ilegalidad fundada en la falta de ley (general o especial que autorice una expropiación) de acuerdo con el art. 9 letra a) del DL 2.186; y atacables asimismo por acciones de nulidad administrativa y civil. Más aún, también resulta posible emplear la acción colectiva que contempla el art. 2 bis letra $b$ ) de la ley que establece normas sobre protección de los derechos de los consumidores, Ley 19.496, en relación con su art. $1^{\circ}$ letra e). Y, finalmente, en los casos en que existiere una gestión judicial pendiente y sentencia que lo habilite, también por vía del recurso de casación en el fondo.

5.- La introducción del art. 139 bis ha significado la derogación tácita de la potestad jurisdiccional o de arbitraje público contenida en el art. 142 de la LGSE, en casos de falta de acuerdo sobre cambios al sistema de suministro requeridos por el concesionario, exclusivamente, en la eventualidad de cambios en el sistema de suministro de SPED implementados por iniciativa propia por los ahora titulares del dominio de los equipos involucrados y que forman parte de la red de distribución.

6.- Los empalmes y medidores son instalaciones eléctricas de consumo en baja tensión y se rigen por la NCh. 4/2003, la Resolución Exenta $\mathrm{N}^{\circ} 468$, de la Comisión Nacional de Energía, que fijó el Anexo Técnico de los Sistemas de Medición, Monitoreo y Control de la Norma Técnica de Calidad de Servicio para los Sistemas de Distribución, y el reciente Reglamento de Seguridad de las instalaciones de consumo de energía eléctrica, aprobado por el D.S. N 8/2020, del Ministerio de Energía. Pero, desde que la red de distribución se amplía hasta los medidores y se 
modifica su régimen de propiedad, existe colisión con la norma técnica, en virtud del cual el derecho colectivo a constituir, administrar y mantener un subsistema de distribución con independencia del concesionario resulta asimismo colateralmente afectado.

7.- El art. 139 bis colisiona con el art. 127 de la LGSE, pues imposibilita los AFR en el caso de ampliaciones de potencia o capacidad por usuarios que aún sean dueños de sus equipos, pues la sola ejecución de lo pedido por parte de la distribuidora gatillaría el cambio de titularidad en la propiedad de los equipos.

8.- El supuesto de exención a un usuario regulado del costo de sólo dos servicios tradicionales (retiro o desmantelamiento y ejecución o instalación), asociados a instalaciones de distribución eléctrica y que no constituyen suministro, es realmente excepcional, residual y restringido: para que la exención proceda se requiere una situación de calamidad fortuita e irresistible (fuerza mayor) en que la autoridad competente haya decretado estado de catástrofe.

9.- En todos los demás supuestos en que se requiriesen esos dos servicios, el cliente es quien debe correr con los gastos. E igualmente por vincularse a la distribución, aunque no constituyan suministro, resulta plausible sostener que los costos de servicios no tradicionales, producto de nuevas funcionalidades de equipos de los SMMC de última generación, también deban ser asumidos por los clientes, aunque no sean de su dominio.

10.- Por último, la inclusión del financiamiento del costo de los nuevos equipos de reemplazo en el régimen tarifario, y en esa condición como un costo de cargo de los usuarios, resulta muy discutible desde el punto de vista de la justicia de resultado ya que se hace pagar a los usuarios por equipamiento que antes del art. 139 bis se habría incorporado a su patrimonio evitándoles el costo asociado de arriendo. En cambio, tras la norma indicada las personas financian el costo de equipos ajenos, que por ley pertenecen a las distribuidoras y por las que éstas, además, están habilitadas para cobrarles arriendo y los demás servicios asociados a la distribución.

11.- En la situación presente, tanto el costo de los equipos nuevos SMMC como el de la gama completa de servicios asociados a su funcionamiento y a la distribución, se incorporan al VAD y adquieren así reconocimiento a nivel tarifario, implicando -al final del día- que sea el usuario quien los asuma financieramente.

12.- El análisis jurídico-económico de la Ley $\mathrm{N}^{\circ} 21.076$ determina un claro menoscabo del beneficio marginal de la sociedad en su conjunto. 
Ello porque, bajo la fachada de una medida pro-usuario de reducidísimo efecto real (servicios asociados en caso fortuito), en verdad no sólo implicó la pérdida de una potestad pública jurisdiccional o de arbitraje (art. 142) y la lesión a la autonomía de un grupo intermedio; sino que también lesionó gravemente contrapesos de los usuarios al poder de mercado de las distribuidoras, todo lo cual contribuyó a posibilitar la existencia de un tradeoff económico resultante de la introducción del art. 139 bis, claramente favorable a los intereses de empresas distribuidoras y en desmedro de los de los usuarios regulados.

En palabras finales y simples, puede decirse que la Ley $\mathrm{N}^{\circ} 21.076$ es el equivalente a una obra de arte jurídico-monopólica en beneficio de los concesionarios de un SPED, que no sólo despojó inconstitucionalmente de la propiedad de los equipos de medición antiguos; sino que contempló -en último término y a través de las tarifas- que fuere el usuario quien financiare el costo de los SMMC nuevos (empalmes y medidores), cuya propiedad y control futuro sobre los datos de la red inteligente pasan a manos de las empresas distribuidoras.

\section{BIBLIOGRAFÍA CITADA}

\section{a) Doctrina y documentos citados}

Biblioteca del Congreso Nacional de Chile (Eds.), Historia de la Ley $N^{o}$ 21.076, que modifica la Ley General de Servicios Eléctricos para imponer a la empresa distribuidora de energía la obligación de solventar el retiro y reposición del empalme y medidor en caso de inutilización de las instalaciones por fuerza mayor, 2019, p. 5, disponible en: https://www.bcn.cl/historiadelaley/nc/historiade-la-ley/7500/

Cámara de Diputadas y Diputados, "Modifica la Ley General de Servicios Eléctricos para imponer a la empresa distribuidora de energía la obligación de solventar el retiro y reposición del empalme y medidor en caso de inutilización de las instalaciones por fuerza mayor”, Proyecto de Ley Boletín $N^{\circ} 10331-08$, Legislatura 363, Sesión 78, 8 de octubre de 2015.

Cámara de Diputadas y Diputados, "Sobre reposición de empalmes y medidores eléctricos", Proyecto de Ley Boletín $\mathrm{N}^{\circ}$ 6899-03, Legislatura 358, Sesión 9, 14 de abril de 2010. 
Cámara de Diputadas y Diputados, Oficio N¹2.756, del 16 de agosto de 2016, en que envía el Proyecto de Ley Boletín $N^{\circ}$ 10.331-08, aprobado, al Senado.

Comisión de Minería y Energía de la Cámara de Diputadas y Diputados, "Informe de Comisión de Minería y Energía en Sesión 21, Legislatura 364, Cámara de Diputadas y Diputados, 11 de marzo de 2016", en: Biblioteca Del Congreso Nacional de Chile (ed.), Historia de la Ley $N^{\circ}$ 21.076, que modifica la Ley General de Servicios Eléctricos para imponer a la empresa distribuidora de energía la obligación de solventar el retiro y reposición del empalme y medidor en caso de inutilización de las instalaciones por fuerza mayor, 2019, disponible en: https:// www.bcn.cl/historiadelaley/nc/historia-de-la-ley/7500/

Comisión de Minería Y Energía del Senado, "Informe de Comisión de Minería y Energía en Sesión 78, Legislatura 365, Senado, 5 de enero de 2018”, en: Biblioteca del Congreso Nacional de Chile (ed.), Historia de la Ley $N^{o}$ 21.076, que modifica la Ley General de Servicios Eléctricos para imponer a la empresa distribuidora de energía la obligación de solventar el retiro y reposición del empalme y medidor en caso de inutilización de las instalaciones por fuerza mayor, 2019, disponible en: https://www.bcn.cl/historiadelaley/nc/historia-de-laley/7500/

Comisión Nacional de Energía, Oficio Ord. N 715/2017, del 19 de diciembre de 2017, dirigido a la Comisión de Minería y Energía del Senado.

García Oviedo, Carlos, Derecho Administrativo, E.I.S.A. Madrid, 1957, $6^{\mathrm{a}}$ ed.

Noticia: "2019, un año para las grandes definiciones de una nueva distribución eléctrica", página de Alster Legal, 23 de enero de 2019, comentario disponible en línea: https:/www.alsterlegal.com/2019/01/23/2019-ano-lasgrandes-definiciones-una-nueva-distribucion-electrica/, consultada al 23 de mayo de 2019.

Samuelson, Paul, "The Pure Theory of Public Expenditure", The Review of Economics and Statistics, 1954, vol. 36, No 4.

Seguel Lizana, Pedro, “Análisis contemporáneo de la institución jurídica de la expropiación”. Universidad Andrés Bello, Santiago, 2013.

SENADO, Oficio No 40/SEC/18, del 17 de enero de 2018, en que devuelve el Proyecto de Ley Boletín $\mathrm{N}^{\circ} 10.331-08$, aprobado con modificaciones, a la Cámara de Diputadas y Diputados.

b) Normas jurídicas citadas

Constitución Política de la República de Chile, 1980.

Decreto con Fuerza de Ley $N^{\circ} 5$, de 2003, del Ministerio de Economía.

Decreto con Fuerza de Ley $\mathrm{N}^{\circ}$ 4, 2007, que fija el texto refundido, coordinado y sistematizado del Decreto con Fuerza de Ley $\mathrm{N}^{\circ}$ 1, de Minería, de 1982, Ley 
General de Servicios Eléctricos.

Decreto Ley No 2.186, de 1978.

Decreto Supremo $N^{\circ} 126$, de 2013, del Ministerio de Energía, que modifica el Decreto Supremo $N^{\circ} 4$, de 2008, del Ministerio de Economía, que aprueba el Reglamento sobre Licitaciones de suministro de energía para satisfacer el consumo de los clientes regulados de las empresas concesionarias del Servicio Público de Distribución de Energía Eléctrica.

Decreto Supremo $\mathrm{N}^{\circ}$ 197, de 2009, del Ministerio de Economía, que fija precios de servicios no consistentes en suministros de energía, asociados a la distribución eléctrica.

Decreto Supremo N ${ }^{\circ}$ 11T, 2016, del Ministerio de Energía, que fija las fórmulas tarifarias para los suministros sujetos a precios regulados.

Decreto Supremo No 5T, 2018, del Ministerio de Energía, que fija las fórmulas tarifarias para los suministros sujetos a precios regulados del Decreto Supremo No 11T, 2016, del Ministerio de Energía.

Decreto Supremo No 8, de 2020, del Ministerio de Energía, que aprueba el Reglamento de seguridad de las instalaciones de consumo de energía eléctrica.

Ley $\mathrm{N}^{\circ}$ 18.046, sobre Sociedades Anónimas, 1981.

Ley $\mathrm{N}^{\circ} 20.928,2016$.

Ley $N^{\circ}$ 21.076, que modifica la Ley General de Servicios Eléctricos para imponer a la empresa distribuidora de energía la obligación de solventar el retiro y reposición del empalme y medidor en caso de inutilización de las instalaciones por fuerza mayor, 2018.

Ley $\mathrm{N}^{\mathrm{0}} 19.646$, que establece normas sobre protección de los derechos de los consumidores, 1997.

Norma Técnica $N^{\circ}$ 4/2003 sobre instalaciones de consumo en baja tensión.

Norma Técnica NSEG 3E.n71 sobre medidores.

Resolución Ex. N ${ }^{\mathrm{o}} 468$, de 12 de agosto de 2019, de la Comisión Nacional de Energía, que fija Anexo Técnico de sistemas de medición, monitoreo y control de la Norma Técnica de Calidad de servicio para sistemas de distribución, de conformidad al artículo $35^{\circ}$ del Decreto Supremo $N^{\circ} 11$, de 2017, del Ministerio de Energía.

Resolución Ex. № 706, de 7 de diciembre 2017, de la Comisión Nacional de Energía, que fija Norma Técnica de Calidad de Servicio para Sistemas de Distribución. 